Original Article

\title{
A RAPID AND SENSITIVE RP-HPLC METHOD FOR THE QUANTITATIVE ANALYSIS OF EMPAGLIFLOZIN IN BULK AND PHARMACEUTICAL DOSAGE FORM
}

\section{MADHURIMA BASAK, SANTHOSH REDDY GOURU, ANIMESH BERA, KRISHNA VENI NAGAPPAN*}

aDepartment of Pharmaceutical Analysis, JSS College of Pharmacy, Ooty, (A Constituent College-JSS Academy of Higher Education and Research), Tamilnadu, India

Email: krisath@gmail.com

Received: 29 Mar 2019, Revised and Accepted: 06 Jun 2019

\section{ABSTRACT}

Objective: The present study aims at developing an accurate precise, rapid and sensitive Reverse Phase High-Performance Liquid Chromatography (RP-HPLC) method for assessing Empagliflozin in bulk drug and in the pharmaceutical dosage form.

Methods: The proposed method employs a Reverse Phase Shim Pack $\mathrm{C}_{18}$ column ( $250 \mathrm{~mm} \times 4.6 \mathrm{~mm}$ id; $5 \mu \mathrm{m}$ ) using a mobile phase comprising of acetonitrile and water in the ratio of $60: 40 \mathrm{v} / \mathrm{v}$ flushed at a flow rate of $1 \mathrm{ml} / \mathrm{min}$. The eluents were monitored at $223 \mathrm{~nm}$.

Results: Empagliflozin was eluted at a retention time of $5.417 \mathrm{~min}$ and established a co-relation co-efficient $\left(\mathrm{R}^{2}>0.999\right)$ over a concentration ranging from $0.0495-100 \mu \mathrm{g} / \mathrm{ml}$. Percentage recovery was obtained between $98-102 \%$ which indicated that the method is accurate. The Limit of Detection (LOD) and Limit of Quantitation (LOQ) were found at $0.0125 \mu \mathrm{g} / \mathrm{ml}$ and $0.0495 \mu \mathrm{g} / \mathrm{ml}$, respectively.

Conclusion: An RP-HPLC method which was relatively simple, accurate, rapid and precise was developed and its validation was performed for the quantitative analysis of empagliflozin in bulk and tablet dosage form (10 and $25 \mathrm{mg}$ ) in accordance to International Conference of Harmonization (ICH) Q2 ( $\left.\mathrm{R}_{1}\right)$ guidelines. The proposed method may aid in routinely analyzing empagliflozin in pharmaceuticals.

Keywords: Empagliflozin, RP-HPLC, Method Optimization, Method Validation

(C) 2019 The Authors. Published by Innovare Academic Sciences Pvt Ltd. This is an open access article under the CC BY license (http://creativecommons.org/licenses/by/4.0/) DOI: http://dx.doi.org/10.22159/ijap.2019v11i5.33281

\section{INTRODUCTION}

Type 2 Diabetes mellitus (T2DM) is a popular chronic metabolic disorder caused by insulin insensitivity and decreased level of insulin secretion. In 2017, International diabetes federation reported that the prevalence of diabetes is $9.4 \%$ of the population with $90-95 \%$ cause being T2DM [1]. Diabetes mellitus is accompanied with risks of cardiovascular morbidity and mortality, The tight "glucocentric" approach to the treatment of diabetes by the precedent antidiabetic drugs delivered a setback. This augmented regimen was aborted when it became apparent that it raises the risk of cardiovascular (CV) mortality (as stated by ACCORD-Action to Control CV Risk in diabetes in 2007) [2]. An appropriate antidiabetic should not only be concerned with rectifying metabolic dysfunction but also to protect the cardiovascular system from the effects of epigenetic changes resulting from hyperglycemia.

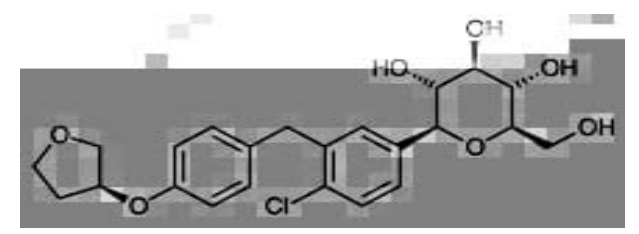

Fig. 1: Chemical structure of Empagliflozin

Empagliflozin is $\quad(2 \mathrm{~S}, 3 \mathrm{R}, 4 \mathrm{R}, 5 \mathrm{~S}, 6 \mathrm{R})-2-[4$-chloro-3-(\{4-[(3S)-oxolan-3yloxy] phenyl\} methyl) phenyl]-6-(hydroxymethyl)oxane-3,4,5-triol having a molecular formula of $\mathrm{C}_{23} \mathrm{H}_{27} \mathrm{ClO}_{7}$ and molecular weight of $450.912 \mathrm{~g} / \mathrm{mol}$ is a orally administered sodium-glucose co-transporter II inhibitor (SGLT-2) (fig. 1). Renal tubular sodium-glucose co-transporter receptors are engaged with elevated reabsorption of tubular glucose [3]. High reabsorption of sodium in the proximal tubule causes decreased shipment of sodium to the macula densa resulting in vasodilation of the afferent arteriole with simultaneous constriction of the efferent arteriole eliciting inter glomerular hypertension [4]. Empagliflozin inhibits the SGLT-2 inhibitor receptors thereby eradicate these effects and concurrently diminishing both preload (by Diuresis) and afterload (by decreasing arteriole stiffness and blood pressure) resulting in considerable reduction in $\mathrm{CV}$ mortality [5]. A review examines the pharmacokinetic characteristics of empagliflozin in healthy individuals, and in patients with T2DM treated with empagliflozin monotherapy [6]. Empagliflozin counters diabetes by inhibiting about $90 \%$ of glucose into the blood and excretes it through urine.

An extensive study of methods prevailing in regard to the assessment of empagliflozin independently and in combination of other antidiabetic drugs has divulged a number of analytical and spectral techniques [7-8].

Madana et al. (2017) divulged that a mobile phase with a concoction of phosphate buffer at $\mathrm{pH} 3$ and methanol in the ratio $30: 70 \mathrm{v} / \mathrm{v}$ when flushed on a dikma $\mathrm{C}_{18}$ column $(50 \times 2.1 \mathrm{~mm}, 1.8 \mu \mathrm{m})$ an RPHPLC method was developed for estimation of empagliflozin in the presence of its degradants [9]. Sushil et al. (2017) have reported an RP-HPLC method for the quantification of empagliflozin using an Intersil $\mathrm{C}_{8}(250 \times 4.6 \mathrm{~mm} \times 5 \mu \mathrm{m})$ column and a mobile phase comprising of $0.1 \%$ orthophosphoric acid and acetonitrile in the ratio 50:50 v/v in gradient elution [10]. Ghadir et al. (2018) publicized a method for evaluation of empagliflozin in routine analysis which was materialized through acetonitrile: $0.05 \mathrm{M}$ Potassium Dihydrogen phosphate buffer at $\mathrm{pH} 4$ in the ratio of 65:35 $\mathrm{v} / \mathrm{v}$ in isocratic mode [11]. Sharmila et al. (2018) proclaimed that determination of empagliflozin in bulk and pharmaceutical dosage form was done through discovery $\mathrm{C}_{18}$ column $(250 \times 4.6 \mathrm{~mm}, 5 \mu \mathrm{m})$ in association with a buffer and acetonitrile in the proportion of 68:32 [12]. Literature pertaining to development of a stabilityindicating RP-HPLC method of empagliflozin revealed that most of the researchers used buffers like acetate, potassium dihydrogen salts or acids like orthophosphoric acid to adjust the $\mathrm{pH}$ for appropriate separation of the analytes. So, this article targets to develop and validate a rather simpler, rapid, precise, accurate, highly sensitive and selective RP-HPLC method that can be used for routine analysis and control of quality in pharmaceutical industries.

\section{MATERIALS AND METHODS}

Chemicals

HPLC grade acetonitrile was acquired from merck industries (Mumbai, India). HPLC grade water was generated, employing a Mili Q water system (Bangalore, India). The reference standard of empagliflozin was received as a gift sample from mylan Industries 
(Hyderabad, India). The marketed formulation was purchased from a local pharmacy, The Nilgiris.

\section{Instrumentation}

Experiments pertaining to HPLC were exercised on shimadzu LC2010A autosampler (Shimadzu Corporation, Kryto, Japan). The system was equipped with a quaternary low pressure mixing pump (LC-2010A) and an UV-detector (Shimadzu SPD-20A), a shim pack solar RP-C 18 column ( $250 \times 4.6 \mathrm{~mm} ; 5 \mu \mathrm{m}$ ), an autosampler with 20 $\mu \mathrm{l}$ aliquots sample loop volume was used for the chromatographic analysis. The software, Class VP data station was employed for data collection and analysis. A shimadzu 1700(E) spectrometer was engaged for recording the UV spectra.

\section{Selection of wavelength}

A standard solution containing $1 \mathrm{mg} / \mathrm{ml}$ empagliflozin in acetonitrile was prepared. From the stock solution. A secondary solution was prepared by dissolving $1 \mathrm{ml}$ of the standard solution in the mobile phase. The standard solution was scanned at wavelengths ranging from 200-400 $\mathrm{nm}$. Empagliflozin exhibited maximum absorbance at $223 \mathrm{~nm}$ (fig. 2). Thus it was stipulated as the $\lambda$ max for surveilling the chromatographic eluents.

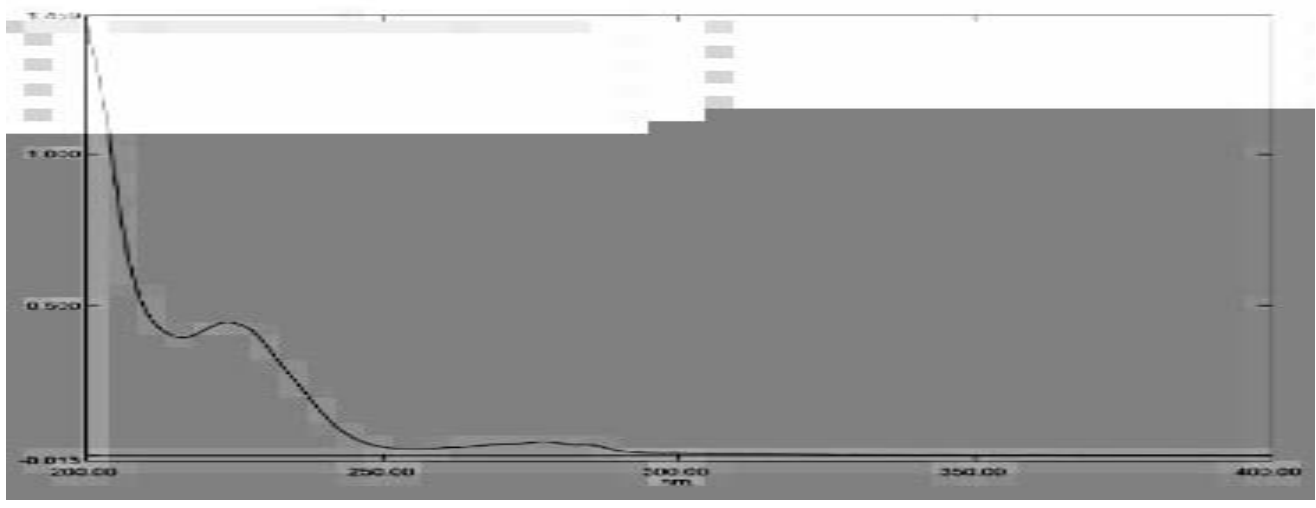

Fig. 2: UV spectra of Empagliflozin

\section{Standard and sample preparations}

$10 \mathrm{mg}$ of empagliflozin API was dissolved in acetonitrile HPLC grade in a $10 \mathrm{ml}$ volumetric flask $(1 \mathrm{mg} / \mathrm{ml})$ for preparing the primary standard. From this standard stock solution a series of dilution viz.; $100 \mu \mathrm{g} / \mathrm{ml}, 10 \mu \mathrm{g} / \mathrm{ml}$ and $1 \mu \mathrm{g} / \mathrm{ml}$ were prepared in the mobile phase, which then served as $100 \%$ target concentration.

\section{Assay of the marketed formulation}

10 film-coated tablets of marketed empagliflozin (10 mg and $25 \mathrm{mg}$ ) were separately weighed and finely powdered in a mortar and pestle and a quantity equivalent to the average weight of the formulation was transferred to two $100 \mathrm{ml}$ volumetric flasks and dissolved in about 60 $\mathrm{ml}$ of mobile phase and sonicated for about $10 \mathrm{~min}$. These solutions were then filtered through whattman filter paper and the volume was adjusted to $100 \mathrm{ml}$ with mobile phase (solution A). $1 \mathrm{ml}$ of solution A was transferred to a $10 \mathrm{ml}$ volumetric flask and the volume was adjusted with mobile phase to obtain a working standard having a concentration of $10 \mu \mathrm{g} / \mathrm{ml}$ and $25 \mu \mathrm{g} / \mathrm{ml}$ respectively. These solutions were analysed in triplicate using optimized chromatographic conditions. The chromatograms were recorded and the amount of the drug present was assessed, standard deviation and the \%RSD (Relative Standard Deviation) was calculated and reported.

\section{Linearity and range}

Linear proportionality of the acquired response to that of the analyte concentration specifies the linearity of the said analytical method. Concentrations ranging between $0.0495-25 \mu \mathrm{g} / \mathrm{ml}$ were assessed for determining the linearity of the proposed method. Preparation of the working standards was done by diluting the primary stock solution bearing the concentration of $1 \mathrm{mg} / \mathrm{ml}$ in mobile phase. These range of concentrations were injected in threefold under chromatographic conditions that have been optimized and the respective chromatograms were documented. The linearity was established based on the co-relation co-efficient obtained by plotting a graph with concentration in $\mu \mathrm{g} / \mathrm{ml}$ at the $\mathrm{x}$ axis and peak area of empagliflozin at the $y$-axis.

\section{Precision and accuracy studies}

Intraday and interday studies assess the precision of the designed method. Six independent injections of three different concentrations i.e. 1, 4, $16 \mu \mathrm{g} / \mathrm{ml}$ Low-Quality Control (LQC), Medium Quality Control (MQC) and High-Quality Control (HQC level) were utilized in the study of the proposed method. Intraday precision, as well as repeatability, was examined by analyzing the samples on the same day and the interday precision was done by analysing these same samples (as used in intraday study) on three different days. Calculations for mean and \%RSD were carried out by using the values obtained from interday and intraday studies.

Recovery studies elicit the accuracy of the method. The accuracy of the method was assessed by the standard addition method, i.e. analysis of the sample solution spiked with the known concentration of the sample prepared from formulation under optimized chromatographic condition. The recovery results acquired from the 3 different levels $(1,4,16 \mu \mathrm{g} / \mathrm{ml})$ of concentrations made way for the calculations of \%mean recovery, standard deviation, and \%relative standard deviation and were reported.

\section{LOD and LOQ}

Sensitivity of a method determines how capable is the method for detecting the lowest possible concentration of analyte without any noise. This is assessed by the parameter of LOD and LOQ. Limit of Detection (LOD) is the smallest concentration of the analyte that can be detected by the developed method which evokes a computable response (signal to noise ratio 3 ) where Limit of quantification(LOQ) is the least concentration of the analyte which generates a response that can be precisely quantified (Signal to noise ratio 10).

LOD and LOQ can be calculated by the formula:

$$
\begin{aligned}
& L O D=\frac{3.3 * \sigma}{S} \\
& L O Q=\frac{10 * \sigma}{S}
\end{aligned}
$$

Where $\sigma=$ Standard deviation of the response; $\mathrm{S}=$ Slope of the deviation curve.

\section{Robustness}

The parameter of ruggedness and robustness of the developed method was scaled by bringing about slight changes in the stated experimental conditions like minute deviations in analyte 
concentrations, source of reagent, various brands of columns and marginal variability in ratio of the mobile phase, flow of eluents etc.

\section{System suitability}

System suitability parameters play a key role in development and validation of an analytical method ensuring the optimal performance of the system. Chromatographic parameters viz; number of theoretical plates $(N)$, retention time $\left(R_{t}\right)$, Resolution $\left(R_{s}\right)$ and asymmetric peak factor (A) were scanned on injecting 6 replicates of the standard empagliflozin at a concentration of $10 \mu \mathrm{g} / \mathrm{ml}$.

\section{RESULTS}

\section{Method development}

The proposed method was designed by optimizing the chromatographic conditions by pertaining to various trial runs altering the mobile phase composition, the ratio of the mobile phase, $\mathrm{pH}$, column, column length to attain symmetrical analyte peak at a sufficiently short run time. Acetonitrile was used as an organic modifier in the mobile phase. Initially, various ratios of acetonitrile and water were employed as the mobile phase for separations, exhibited peak asymmetry.

Finally, asymmetric analyte peak with an acceptable short run time was achieved employing acetonitrile and water in a ratio of 40:60 $\mathrm{v} / \mathrm{v}$ at a flow rate of $1 \mathrm{ml} / \mathrm{min}$, with a Shim pack $\mathrm{C}_{18}(250 \mathrm{~mm}$ X 4.6 $\mathrm{mm}, 5 \mu \mathrm{m}$ ) being utilized as the stationary phase and the eluents were monitored at a wavelength of $223 \mathrm{~nm}$.

Empagliflozin was eluted at $5.45 \mathrm{~min}$. The mobile phase was prepared by filtering through a $0.45 \mu$ PTFE (Poly Tetra fluoro ethylene) membrane filter before incorporating in the HPLC system. Class VP data station recorded and processed the chromatograms.

\section{Method validation}

The RP-HPLC method that was developed was targeted for quantifying empagliflozin and validation of the designed method was carried out in accordance to the ICH guidelines for the parameters namely linearity, precision, specificity, accuracy, robustness, ruggedness, detection limit and quantitation limit [13].

\section{Specificity/selectivity}

The specificity of the method was illustrated by injecting the diluents, standard solution of empagliflozin and the sample solution extracted from the tablet formulation for any co-eluting peaks within the retention time of the drug $(5.45 \pm 0.05 \mathrm{~min})$. No co-eluting peak was observed, a sharp and symmetric peak shape demonstrated the specificity of the method. The chromatograms of the sample solutions and standards are depicted in fig. 3 and 4.

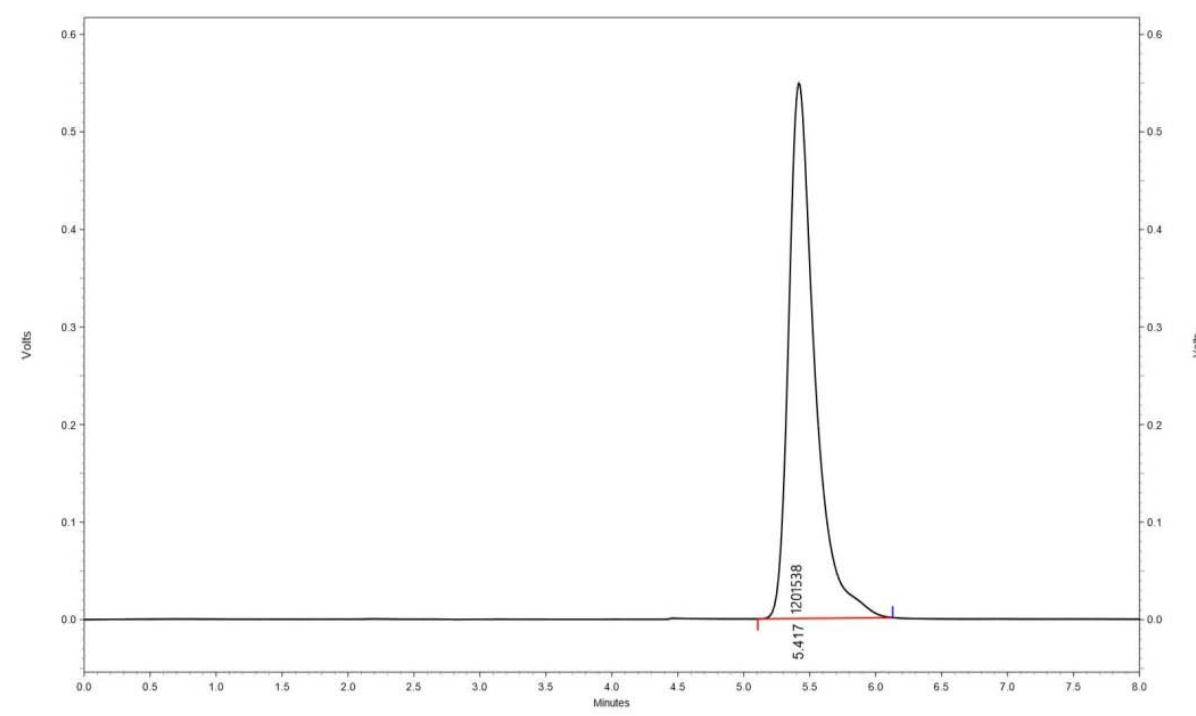

Fig. 3: Typical chromatogram of the standard solution (Empagliflozin-10 $\mu \mathrm{g} / \mathrm{ml}$ )

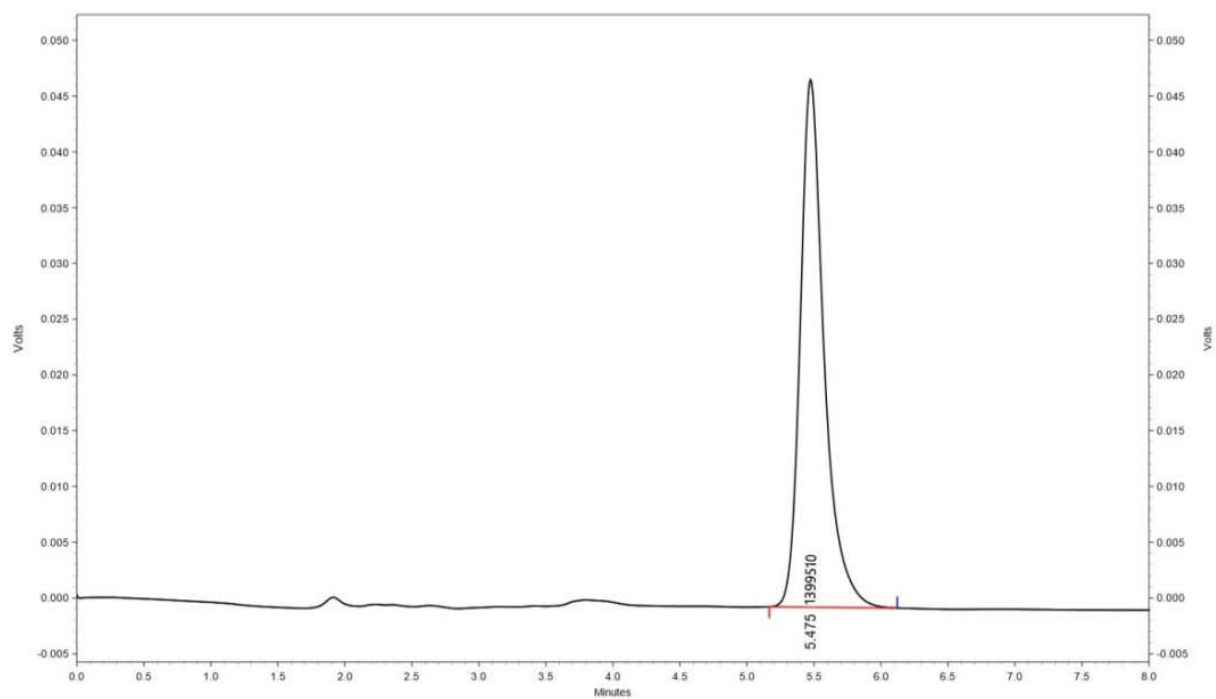

Fig. 4: Typical chromatogram of the sample solution extracted from tablet dosage form (10 $\mathrm{mg}$ tablet) 


\section{Accuracy and precision}

The accuracy of the devised method was demonstrated as the percentage recovery at the concentrations of $1,4,16 \mu \mathrm{g} / \mathrm{ml}$ with the aid of the standard addition method. The threefold analysis was excercised for each level and the mean \% recovery was calculated.
The accuracy of the developed method was found to be ranging between 98\%-102\% (table 1). Assay of the marketed tablet formulation was also performed and reported. The obtained result is on par with label claim and has been enumerated in table 2 . The intraday and inter-day precision studies carried out showed a \% RSD of $<2 \%$ indicating the precision of the method (table 3 ).

Table 1: Accuracy studies of Empagliflozin

\begin{tabular}{llll}
\hline S. No. & Actual concentration $(\boldsymbol{\mu g} / \mathbf{m l})$ & Recovered concentration $\boldsymbol{*}(\boldsymbol{\mu g} / \mathbf{m l}) \pm$ SD; $\%$ RSD & Percentage recovered \\
\hline 1 & 1 & $0.98 \pm 0.005 ; 0.58$ & $98 \%$ \\
2 & 4 & $3.96 \pm 0.015 ; 0.38$ & $99 \%$ \\
3 & 16 & $15.97 \pm 0.015 ; 0.09$ & $99.8 \%$ \\
\hline
\end{tabular}

*mean of 03 determinations

Table 2: Assay of marketed formulations

\begin{tabular}{llll}
\hline S. No. & Sample & Label claim & Amount present \\
\hline 1 & Formulation-I & $10 \mathrm{mg}$ & $9.83 \pm 0.040 ; 0.410$ \\
2 & Formulation-II & $25 \mathrm{mg}$ & $24.83 \pm 0.051316 ; 0.206$ \\
\hline
\end{tabular}

*mean of 03 determinations

Table 3: Precision studies of Empagliflozin

\begin{tabular}{llll}
\hline S. No. & Concentration $(\boldsymbol{\mu g} / \mathbf{m l})$ & Intraday mean* $\mathbf{m}$ SD; $\%$ RSD (n=6) & Interday mean* \pm SD; \%RSD (n=6) \\
\hline 1 & $1(\mathrm{LQC})$ & $0.9917 \pm 0.0090 ; 0.915$ & $0.9875 \pm 0.0077 ; 0.787$ \\
2 & (MQC) & $3.9209 \pm 0.0031 ; 0.079$ & $3.9701 \pm 0.0723 ; 1.822$ \\
3 & $16(\mathrm{HQC})$ & $15.9556 \pm 0.0335 ; 0.210$ & $15.9000 \pm 0.0713 ; 0.448$ \\
\hline
\end{tabular}

*mean of 03 determinations, (LQC-Low-Quality control; MQC-Middle-Quality Control; HQC-High-Quality Control samples)

\section{Linearity}

Six different concentrations against corresponding peaks were plotted for developing the calibration curve. The graph showed excellent correlation between the concentrations and peak area when observed within the range of $(0.0495-25 \mu \mathrm{g} / \mathrm{ml})$ for empagliflozin. The co-relation co-efficient for empagliflozin was $\geq$ 0.998, the slope and the intercept were depicted at 91860 and 3837 respectively. The graph depicting linearity of the method is represented in fig. 5 .

Table 4: Linearity

\begin{tabular}{ll}
\hline Conc of the drug $(\boldsymbol{\mu g} / \mathbf{m l})$ & Peak area* \\
\hline 0.0495 & 4937 \\
0.099 & 9734.5 \\
0.1988 & 19408.5 \\
0.39 & 39239.5 \\
1.7812 & 84657.5 \\
1.56 & 153479 \\
3.125 & 301288 \\
6.25 & 593940.5 \\
12.5 & 1149073.5 \\
25 & 2286462.5 \\
Regression Co-efficient & Y=91860x-3837 \\
Correlation Co-efficient & 0.998 \\
\hline
\end{tabular}

${ }^{*}$ mean of six determinations

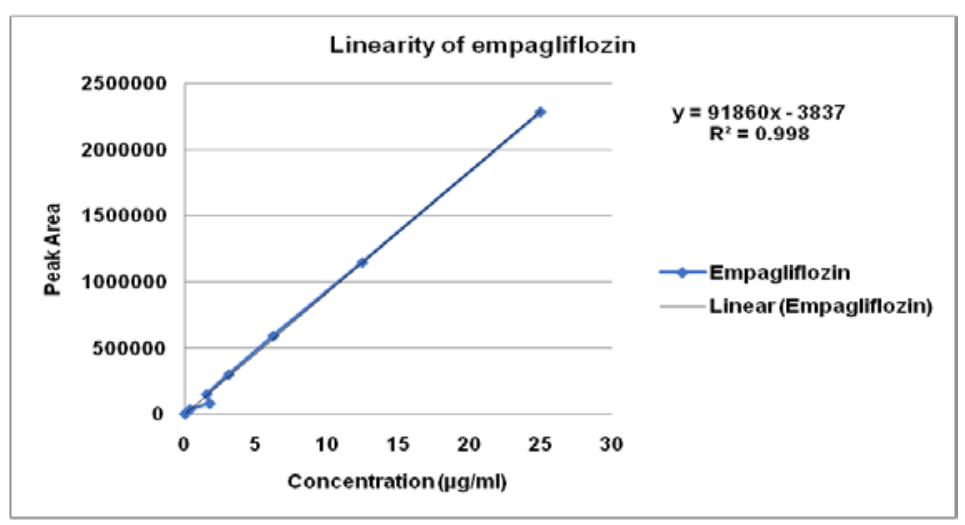

Fig. 5: Linearity plot of empagliflozin 


\section{Detection limit and quantification limit}

The detection and quantification limit illustrates the sensitivity of the devised method. The LOD and LOQ were found to be $0.0125 \mu \mathrm{g} / \mathrm{ml}$ and $0.0495 \mu \mathrm{g} / \mathrm{ml}$, respectively indicating the sensitivity of the method. These results have been tabulated in table 5 .

\section{System suitability}

Six replicates of the standard at working concentrate were injected to observe changes in separation, retention time and asymmetry of the peaks and validate the system suitability parameters. The system suitability was found to be within limits and are summarized in table 6 .

Table 6: System Suitability parameters

\begin{tabular}{lll}
\hline S. No. & Parameters & Empagliflozin \\
\hline 1. & Retention time (min) & 5.417 \\
2. & Theoretical plates (N) & 2014 \\
3 & Tailing Factor & 0.67 \\
4 & Asymmetry factor (A) & 1.0 \\
5 & Regression coefficient (R $\left.{ }^{2}\right)$ & 0.998 \\
6 & Regression equation & Y=91860x-3837 \\
7 & Linearity and Range & $0.0495-25 \mu \mathrm{g} / \mathrm{ml}$ \\
8 & Detection Limit (LOD) & $0.0125 \mu \mathrm{g} / \mathrm{ml}$ \\
9 & Quantification Limit (LOQ) & $0.0495 \mu \mathrm{g} / \mathrm{ml}$ \\
\hline
\end{tabular}

Table 7: Robustness results

\begin{tabular}{llll}
\hline S. No. & Parameters & & Retention time (min) \\
\hline & Mobile phase ratio & $58: 32$ & $5.25 \pm 0.2$ \\
1. & (Acetonitrile: Water) & $60: 40$ & $5.45 \pm 0.2$ \\
& & $62: 38$ & $5.58 \pm 0.2$ \\
& & 17 & $5.42 \pm 0.2$ \\
2. & Temperature $\left({ }^{\circ} \mathrm{C}\right)$ & 22 & $5.45 \pm 0.2$ \\
& & 27 & $5.43 \pm 0.2$ \\
& Flow rate & 0.8 & $5.40 \pm 0.2$ \\
& (ml/min) & 1 & $5.45 \pm 0.2$ \\
\hline
\end{tabular}

\section{Robustness}

A slight alteration in the flow rate $( \pm 0.2 \mathrm{ml} / \mathrm{min})$, column temperature $\left( \pm 5^{\circ} \mathrm{C}\right)$ and organic phase composition by $\pm 2 \%$ variations exhibited no significant changes in the chromatographic parameters corroborating the developed method to be robust (table 7).

\section{DISCUSSION}

A constructive attempt has been made for this RP-HPLC method to achieve reliable quantification of empagliflozin and its stressed degradants. Optimization has been done after trials executed through variable columns and mobile phases for attaining a costeffective and acclimatized conditions. The design of a method depends upon the nature of the sample (ionic or ionizable, hydrophobic or hydrophilic) and its degree of solubility. Since empagliflozin is found to be readily soluble in polar solvents, therefore RP-HPLC method was deemed to be appropriate for its separation as reversed-phase chromatography. It is a technique using alkyl chains covalently bonded to the stationary phase particles in order to create a hydrophobic stationary phase, which has a stronger affinity for hydrophobic or less polar compounds. Reversed-phase chromatography employs a polar (aqueous) mobile phase. As a result, hydrophobic molecules in the polar mobile phase tend to adsorb to the hydrophobic stationary phase, and hydrophilic molecules in the mobile phase will pass through the column and are eluted first. The developed method has achieved optimum system suitability parameters and possess a simple mobile phase of isocratic mode where other reported methods are with various buffers [6][8][14], temperature [14] and $\mathrm{pH}[6]$ imparted conditions, current method is sensitive enough till $0.0125 \mu \mathrm{g} / \mathrm{ml}$ as LOD, $0.04951485 \mu \mathrm{g} / \mathrm{ml}$ as LOQ and found to be in range up to $25 \mu \mathrm{g} / \mathrm{ml}$ (table 4). Method got established with reliable system suitability parameters. Validation for the method was performed as per ICH guidelines Q2R1, Accuracy was achieved using tablet formulations with two different label claims (table 1) and precision was performed in intraday as well as interday for the LQC, MQC and HQC concentrations with three determinations each have attained \%RSD values in limits (table 3). Method claims to be robust from findings through varying conditions of selected parameters.

\section{CONCLUSION}

A RP-HPLC method that has been made rapid, simple, accurate, precise and sensitive was designed and developed for empagliflozin and the developed method was validated as per ICH guidelines. The drug showed good linearity over concentrations ranging from 0.0495 to $25 \mu \mathrm{g} / \mathrm{ml}$. Recovery studies that were carried out expressed the accuracy of the method. The mean recovery of the validated method ranged between $98-102 \%$.

\section{ACKNOWLEDGEMENT}

The authors are immensely gratified to Mylan laboratory, Hyderabad, India for the gift sample of Empagliflozin (API).

\section{AUTHORS CONTRIBUTIONS}

All the author have contributed equally

\section{CONFLICTS OF INTERESTS}

\section{Declared none}

\section{REFERENCES}

1. https://diabetesatlas. org/resources/2017-atlas.html. [Last accessed on 12 Mar 2019]

2. Tabish A Syed. Is diabetes becoming the biggest epidemic of twenty-first century? Int J Health Sci 2007;1:8-5.

3. Scheen JA. Pharmacokinetic and pharmacodynamic profile of Empagliflozin, a sodium-glucose co-transporter 2 inhibitor. Clin Pharmacokinet 2014;53:225-13.

4. Shubrook JH, Bokaie BB, Adkins SE. Empagliflozin in the treatment of type 2 diabetes: evidence to date. Drug Des Dev Ther 2015;9:5803-793.

5. Raut SM, Maheswari A. Empagliflozin: novel antidiabetic and pro-cardiac drug. Indian J Anaesth 2017;61:440-1.

6. Nermeen A. Review on the pharmacokinetics of empagliflozin, an inhibitor of the sodium-glucose cotransporter-2. Asian J Pharm Clin Res 2017;10:50-6.

7. Geetha SP, Lakshmana RK, Prasad KRS, Suresh BK. Development and validation of stability-indicating reversed 
phase high-pressure liquid chromatography method for simultaneous estimation of metformin and empagliflozin in bulk and tablet dosage form. Asian J Pharm Clin Res 2016;9:126-35.

8. Padmaja N, Veerabhadram G. Method development and validation of RP-HPLC for the estimation of empagliflozin in API. Int J Pharm Sci Res 2016; 7:727-4.

9. Madana Gopal N, Sridhar C. A validated the stability-indicating ultra-performance liquid chromatographic method for simultaneous determination of metformin hydrochloride and empagliflozin in bulk drug and tablet dosage form. Int J Appl Pharm 2017;9:45-50.

10. H Jaiswal Sushil, Katariyal MV, Katariyal V, R Katariya, GS Karva, Koshe Kishor. Validated stability Indicating RP-HPLC method for determination of process-related impurities in Empagliflozin drug substances. World J Pharm Res 2017;6:1037-27.
11. Khalil A Ghadir. Salama Ismail, Gomaa S Mohammed, Helal A Mohammad. Validated PR-HPLC method for simultaneous determination of canagliflozin, dapagliflozin, empagliflozin, and metformin. IJPCBS 2018;8:13-1.

12. Donepudi Sharmila, Achanta Suneeta. Validated HPLC-UV method for simultaneous estimation of Linagliptin and empagliflozin in Human plasma. Int J Appl Pharm 2018;10:56-61.

13. International Conference on Harmonization of Technical Requirements for Registration of Pharmaceuticals for Human use. Validation of Analytical Procedures: Text and Methodology ICH Q2 (R1); 2005.

14. Geetha SA, Rajitha G, Ramya YY, Uma P. Analytical method development and validation of new stability-indicating reverse-phase high-performance liquid chromatography method for simultaneous estimation of metformin hydrochloride and empagliflozin in tablet dosage form. Asian J Pharm Clin Res 2019;12:241-4. 